\title{
International Graduate Students' Second Language Acquisition in Their Acculturation: A Research Synthesis
}

\author{
Eunjeong Park ${ }^{1}$ \\ ${ }^{1}$ College of Education and Human Ecology, The Ohio State University, USA \\ Correspondence: Eunjeong Park, College of Education and Human Ecology, The Ohio State University, USA. Tel: \\ 1-614-292-1364. E-mail: park.1752@osu.edu
}

Received: May 23, 2016

Accepted: July 22, 2016

Online Published: August 9, 2016

doi:10.5430/elr.v5n3p21

URL: http://dx.doi.org/10.5430/elr.v5n3p21

\begin{abstract}
Recognizing a paradigm shift from the cognitive-interactionism associated with Piagetian developmental psychology (e.g. 1974) to Vygotsky's sociocultural theory of mind (Vygotsky, 1978), this paper examines qualitative, quantitative, and mixed-methods studies on international graduate students' second language acquisition (SLA) and learning in their acculturation by conducting a research synthesis. The research synthesis of acculturation will encourage second language researchers to unveil international graduate students' SLA in acculturation within social turns of SLA.
\end{abstract}

Keywords: Acculturation, International students, Research synthesis

\section{Introduction}

In the past few decades, the focus on the second language acquisition (SLA) theory has shifted. Once an exclusively cognitive approach, SLA has paid attention to a sociolinguistic/sociocultural approach in social turns in SLA (Block, 2003). The argument about the sociocultural approach to the SLA theory started from the Firth and Wagner's (1997) critique of the cognitive only approach to SLA. They criticized the distinction between second language (L2) use and learning/acquisition made by SLA mainstream researchers. SLA used to be treated as the assimilation of linguistic data isolated from the context of its use.

The sociolinguistic SLA models are closely connected to environmental factors affecting L2 learners' competence. One example of sociolinguistic SLA models may be Schumann's Acculturation Model (1976). Schumann (1986) defined acculturation as "the social and psychological integration of the learner with the target language (TL) group" (p. 379) and maintained that the social and psychological contact with the target language group is the essential component in acculturation relevant to SLA. SLA is one aspect of acculturation and the degree to which learners acculturate to the target language group will control the degree to which they acquire the second language.

Acculturation normally occurs socio-culturally in a target language setting when L2 learners interact with native speakers of the target language, acquiring the target language not only linguistically but also socially and culturally in the L2 context. Norton (1995) underlined the significance of Schumann's model in the socio-cultural context of language learning, indicating that successful language learning takes place when language learners and speakers of the target language interact.

Despite its significance, Schumann's model seems to be limitedly employed in SLA. Doughty and Long (2003) assumed that Schumann's model can be only applied to natural settings in a daily life. This indicates that Schumann's model may not explain foreign and second language learners' acculturation processes in the classroom. Since more and more international students go abroad to study in English-speaking countries, it is necessary to explore their acculturation in the classroom setting.

Hence, this paper examines qualitative, quantitative, and mixed-methods studies on international graduate students' second language acquisition and learning (Note 1) in their acculturation by conducting a research synthesis. The research synthesis of acculturation will encourage L2 researchers to unveil international graduate students' acculturation in their phases of second language acquisition and learning within social turns of SLA.

\section{Research Questions}

This paper focuses on the following questions based on the reviewed publications. The first two questions were answered through the review of both qualitative and quantitative publications: 
1) How are the following constructs defined: acculturation, adaptation, and adjustment?

2) In what contexts is acculturation being investigated?

The rest of the three questions were answered through qualitative and quantitative publications separately:

3) What methodologies were involved in the qualitative and quantitative studies?

4) What factors influenced (facilitated or hindered) the participants' acquiring a second language in their acculturation in the qualitative and quantitative studies?

5) What directions are recommended for future research in the qualitative and quantitative studies?

\section{Schumann's Acculturation Model}

In terms of language learners being acculturated into a new culture, in the 1970s, Schumann (1976) proposed the Acculturation Model (a.k.a the Piginization Hypothesis) based on the findings from his case study of Alberto, a 33-year-old Costa Rican who was not able to make progress beyond basic pidginized English in Boston, and predicted acculturation as the most significant factor of successful language learning. He claimed that success in L2 acquisition is attributed to the degree and quality of contact with the target language and culture. He related the extent of social and psychological distance between the learner and the target culture.

Schumann (1986) explicated the acculturation model of second language acquisition based on social psychology, claiming that social and psychological contact with the target language group is an essential component in acculturation relevant to SLA. SLA is one aspect of acculturation and the degree to which learners acculturate to the TL group will control the degree to which they acquire the second language.

Barjesteh and Vaseghi's (2012) review paper on the acculturation model for SLA problematized the expansion of SLA research and maintained that theorizing in SLA should follow extensive and rigorous empirical research. According to their critique, Schumann's acculturation model is appealing due to its attempt to explicate the potential "whys" of SLA. Despite the critical impact on the literature of SLA, the acculturation model has gained a limited support in empirical studies. Barjesteh and Vaseghi (2012) pointed out some weaknesses of the Schumann's model that it accounts for language learning in immigration situations, but there may be other influential variables that can explain SLA in acculturation. The limitation of the acculturation model may elucidate why few empirical studies of the acculturation model exist in the field of SLA. However, it is still crucial to keep the Schumann's acculturation model in mind in light of its significance. For these reasons, this research synthesis extends the scope of acculturation, focusing not only on the Schumann's acculturation model but also on various uses of the term, "acculturation," with regard to SLA in the reviewed articles.

\section{Research Synthesis}

Norris and Ortega (2007) pointed out that "the traditional reviewing approach offers no specific set of methods or strategies for reviewing, making it more of a mysterious art than most other research genres" (p. 806). They argued that the traditional reviewing approach heavily rely on the content knowledge of the research. However, it does not usually manifest other research domains, such as methodology and implication. As a result, Norris and Ortega strived to develop a genre of writing, a "research synthesis" (p. 805), by collecting and analyzing the previous studies and identify three characteristics of systematic research reviews: a rational selection of the previous studies, a direct report of the data, and the use of coding books or protocols.

Norris and Ortega (2007) specified potential benefits and limitations of research syntheses. First, research syntheses provide a chance to investigate moderating variables, which may not have been focused on in the previous research. Second, they allow for new theory-oriented knowledge, which has not been considered as a contributing portion in the relevant discipline. Third, varieties and diversity may be evolved through descriptive analyses by constructing interpretations of the results in the previous research. Last, research syntheses can detect gaps, weaknesses, and needs in former research. Despite the potential benefits via research syntheses, Norris and Ortega (2007) described limitations of research syntheses. One limitation would be how much researchers can chase the data and whether there are enough studies regarding target research topics. In particular novel fields or themes may not be feasible for conducting a research synthesis owing to insufficient data. Another limitation is to incorporate "[t]echnical expertise in synthetic methods [and] deep knowledge of the theoretical and conceptual issues at stake in the research domain" (p. 810). It must be difficult for novice or unexperienced researchers to implement a research synthesis with crude expertise of synthetic methods and superficial understandings of the research topic. It is crucial to understand the process of research syntheses before executing them. 


\section{Methodology}

This research synthesis was conducted with two respective phases for involving different paradigms: qualitative and quantitative research. Procedures of each search were alike by following Kohls and Wilson's (2012), and Norris and Ortega's (2007) research syntheses. Key terms, such as "acculturation," "second language acquisition," "international students," and "graduate students," were used in the three major research databases lists: ERIC (EBSCO), ERIC (U. S. Dept of Education), and Education Research Complete. The search controlled the time frame of publications from 1994 to 2014. All of the data included peer-reviewed articles. The articles that dissatisfy the inclusion criteria (Note 2) based on the research questions were disregarded. Through the reviewing process, 15 qualitative, 12 quantitative, and four mixed-method articles were finely tuned for conducting the research synthesis.

\section{Findings}

\subsection{What Are Acculturation, Adaptation, and Adjustment?}

It is important to review definitions of acculturation, adaptation, and adjustment from the previous research. Because these terms are closely related with each other, they may be mistakenly or inappropriately used in research. Across 31 publications (15 qualitative, 12 quantitative, \& 4 mixed-methods), 20 studies indicated a definition of acculturation, adaptation, and adjustment. Acculturation is distinguished from adaptation and adjustment; however, adaptation and adjustment were used interchangeably. Two studies (e.g., Lam, 1994; Yan \& Berliner, 2011) posited acculturation with an operationalized definition. Lam (1994) referred to acculturation as one of the most important variables to illuminate why behaviors are diverse among students from the same cultural background in the English-speaking classroom. Lam (1994) stated that acculturation may be expedited through previous exposure and language learning in the classroom. Yan and Berliner (2011) differentiated two levels of acculturation: the group-level and the individual-level. The group-level (macro-level) acculturation indicates that mobile groups considerably vary due to the two sets of cultural influences, while the individual-level (micro-level) acculturation occurs as a result of several factors, including age, gender, and education. Through operationalizing and measuring a degree of acculturation, the two studies explored the participants' observable changed behaviors and correlate them with their acculturation.

Several authors (e.g., Bang \& Montgomery, 2013; Cheng \& Erben, 2011; Lam, 1994) borrowed the definition of acculturation from the established model, such as Schumann's acculturation model. Schumann (1986) connected acculturation to second language acquisition with its definition: "the social and psychological integration of the learner with the target language (TL) group" (p. 379). Most authors agreed upon the idea that acculturation occurs to new comers who learn a new culture and language in a process of adaptation. For instance, Cheng and Fox (2008) defined acculturation as "the dynamic adaptation processes of linguistically and culturally diverse students engaging with the academic study cultures" (p. 309). Cheng and Erben (2011) also stated that "acculturation is an individual's process of adaptation and socialization, in which members of one cultural group accept the beliefs and manners of the host culture" (p. 479). In the same vein, Bang and Montgomery (2013) referred to acculturation as an individual's adjustment process of the interactional dynamics between two or more cultural systems.

Five quantitative studies (Jiang et al., 2009; Lee, 2014; Lowinger, et al., 2014; Noels et al., 1996; Wadsworth et. al, $2008)$ adopted Berry's operational definition of acculturation. Berry $(1980,1995)$ defined acculturation as the contact between cultures and the dynamic psychosocial changes among the people involved. Jiang, et al's (2009) study explicated that the more psychologically integrated into the target language group, the more likely the learner is able to succeed in L2 acquisition. Hence, Jiang et al.'s (2009) study indicated that "the essence of successful L2 acquisition is to identify with, and get involved in, the target culture socially and affectively" (p. 482). Lee (2014) and Lowinger, et al.'s (2014) studies also maintained that the process of acculturation involves changing attitudes toward host and home cultures with the Berry's (2005) explanation of acculturation as "the dual process of cultural and psychological change that takes place as a result of contact between two or more cultural groups and their individual members" (p. 698). As can be seen, the term of acculturation is well-defined theoretically and operationally; thus, researchers should employ the notion of acculturation with a thorough consideration. 
Table 1. Definition of Acculturation

\begin{tabular}{|c|c|}
\hline & Theoretical definition \\
\hline Schumann (1986) & The social and psychological integration of the learner with the target language group \\
\hline Lam (1994) & The association of previous exposure with classroom learning \\
\hline Cheng \& Fox (2008) & $\begin{array}{l}\text { The dynamic adaptation processes of linguistically and culturally diverse students } \\
\text { engaging with the academic study cultures }\end{array}$ \\
\hline Cheng \& Erben (2011) & An individual's process of adaptation and socialization in the host culture \\
\hline \multirow[t]{2}{*}{$\begin{array}{l}\text { Bang\&Montgomery } \\
(2013)\end{array}$} & $\begin{array}{l}\text { An individual's adjustment process of the interactional dynamics between the two } \\
\text { cultural systems }\end{array}$ \\
\hline & Operationalized definition \\
\hline $\begin{array}{l}\text { Berry }(1980, \\
2005)\end{array}$ & $\begin{array}{l}\text { The dual process of cultural and psychological change as a result of the contact } \\
\text { between cultures and the dynamic psychosocial changes among the people }\end{array}$ \\
\hline Yan \& Berliner & Macro-level: the variability of two sets of cultural influences \\
\hline \multirow[t]{2}{*}{ (2011) } & Micro-level: the individual factors of demographics and pull $\&$ push motivation \\
\hline & Correlation of observable changed behaviors and acculturation levels \\
\hline
\end{tabular}

Adaptation and adjustment appeared in the seven articles (Kashima \& Loh, 2006; Kim, 2012; Poyrazli \& Grahame, 2007; Ren, et al., 2007; Wadsworth, et al., 2008; Wang \& Mallinckrodt, 2006; Yuan, 2011) with the use of adaptation and adjustment interchangeably. Kim (2012) demonstrated a definition of adaptation or adjustment from various scholars (Anderson, 1994; Bowers, 1973; Ramsay, Barker, \& Jones, 1999) and defined adaptation or adjustment as a process of appreciation and acquisition of the target culture in an academic situation. Studies of adaptation or adjustment have analyzed the process by dividing it into four components: a cultural encounter, an experience of obstacles, response generation, and the overcoming phase (Kim, 2012; Ramsay, Barker, \& Jones, 1999).

Table 2. Definition of Adaptation/adjustment

\begin{tabular}{lll}
\hline & Adaptation/adjustment \\
\hline $\begin{array}{l}\text { Kashima } \\
\text { Loh (2006) }\end{array}$ & $\begin{array}{l}\text { Psychological adjustment as the main effects of local, conational, and international ties after } \\
\text { controlling for English-speaking background and length of residence }\end{array}$ \\
$\begin{array}{l}\text { Wang } \\
\text { Mallinckrodt }\end{array}$ & $\begin{array}{l}\text { Psychological adjustment as emotional well-being, measured by assessing self-reported } \\
\text { psychological symptoms and perceived distress; }\end{array}$ \\
& $\begin{array}{l}\text { Sociocultural adaptation as the ability to acquire and perform culturally appropriate social } \\
\text { skills and behavioral competence to fit in the host culture }\end{array}$ \\
Kim (2012) & A process of appreciation and acquisition of the target culture in an academic situation
\end{tabular}

Reviewing the definitions of acculturation, adaptation, and adjustment, the scope of acculturation should not be limited to only cognitive-interactionist orientation on SLA (i.e., Shumann's Acculturation Model). This is because acculturation is quite a complicated term that is related to psychological and intercultural contact (Kormos, et al., 2014), which cannot be accounted for SLA only with the cognitive orientation.

\subsection{In What Contexts Is SLA in the Acculturation Being Investigated?}

This paper focuses on international graduate students whose first language is not English. Their second language acquisition and learning in acculturation occurred in university and college settings in English-speaking countries. The majority of the studies ( 27 out of 31 studies) were conducted in U.S. universities and colleges. Four publications (e.g., Kormos et al., 2014; Kashima \& Loh, 2006; Liu, 2011; Noels, et al., 1996) located their sites in non-U.S. contexts: Australia, Canada and the United Kingdom. Hebbani \& Hendrix's (2014) study is also relevant to the U.S., but their research delved into international teaching assistants' perceptions toward American undergraduates by examining qualitative-oriented survey responses. Of 27 U.S. university contexts, 21 studies were conducted in large universities; two studies (e.g., Lin \& Scherz, 2014; Yuan, 2011) in medium-sized institutions; one study (e.g., Poyrazli \& Grahame, 2007) in a small-sized semi-urban college. The other three studies (e.g., Hsieh, 2007; Lam, 1994; Sandhu \& Asrabadi, 1994) did not specify the magnitude of the context. 
A noticeable point regarding SLA was discovered in Poyrazli and Grahame's (2007) study about the needs of international students within a semi-urban campus community. The study revealed that its academic context, the relatively small college, made minority ethnic groups more visible, so Asian students accents were treated as a problem. Furthermore, local students usually commute to classes while international students live on campus, which made international students unable to interact with native speakers of English. This can signify that where you live is a crucial context to international students' SLA in acculturation.

\subsection{What Methodologies Were Involved in the Studies? (Note 3)}

\subsubsection{Methodologies in Qualitative Studies}

The reviewed 15 studies ranged in qualitative approaches for exploring SLA in acculturation. Two studies (e.g., Hsieh, 2012; Liu, 2011) were involved in a narrative approach. Several studies focused on three different approaches to qualitative research, including an ecological framework (e.g., Poyrazli \& Grahame, 2007), a naturalistic and interpretive approach with the use of Leximancer for content analysis (e.g., Hebbani \& Hendrix, 2014), and a phenomenological approach (e.g., Lin \& Scherz, 2014; Xue, 2013).

Poyrazli and Grahame's (2007) study utilized an ecological framework because the attention to the concerns as simply individual problems is insufficient. Rather, the social system should be a main focus since it promotes or inhibits international students' acculturation. Hebbani and Hendrix's (2014) naturalistic interpretative approach delved into a paradigm that acknowledges: (a) multiple realities, (b) the minimized distance between researcher and participant, (c) researcher as embodied instrument, (d) the presence of value judgments in all empirical work, and (e) specialized rhetorical framing of an investigator's findings, to explore phenomena in the students' acculturation. In a similar way, Lin and Scherz's (2014) phenomenological research focused on a phenomenon that delineates the commonality of participants, allowing researchers' integration into the research context and situations and an emerging framework to develop through the analysis of the participants' responses.

Twelve qualitative studies were conducted with interviews, observation, and questionnaires (e.g., Hebbani \& Hendrix, 2014; Kim, 2007; Lam, 1994; Lee, 2009; Lin \& Scherz, 2014; Poyrazli \& Grahame, 2007; Ren et al., 2007; Xue, 2013; Yan \& Berliner, 2011, 2013; Yuan, 2011; Zhou et al., 2011). Kim's (2012) study explored adaptation and adjustment in the U.S. research-based universities by implementing 50 open-ended interviews over 5.5-year period (from December 1999 to May 2005) as longitudinal qualitative research.

Through the analysis of the method sections in the 15 qualitative studies, exploring international students' SLA in acculturation seems to require qualitative research due to a chain of reasoning. Duff and Talmy (2011), in particular, agreed that sociocultural, sociocognitive, and ecological approaches represent a philosophical and metaphorical framework to ground on SLA frameworks. An attempt to conduct research based on these frameworks (e.g., ecological, naturalistic and interpretive, and phenomenological approaches) will inspire more L2 researchers to examine phenomena of SLA in acculturation with these innovative but concrete paradigms.

\subsubsection{Methodologies in Quantitative Studies}

In the 12 quantitative studies, the most frequently employed methods for analyzing numerical data were correlation, multiple regression, and factor analyses. A correlation analysis was used in three studies (Lowinger et al., 2014; Noels et al., 1996; Rubenfeld, et al., 2007). Lowinger et al.'s (2014) study examined the relations among academic self-efficacy, acculturation difficulties, and language abilities on procrastination behavior. Noels et al.'s (1996) study investigated the relations among identity, language, and adjustment variables with correlation and path-analytic techniques. Rubenfeld, et al.'s (2007) study examined correlations between acculturation and intrinsic/extrinsic motivation to language learning.

A factor analysis is the subsequent quantitative method in three studies (Bang \& Montgomery, 2013; Sandhu \& Asrabadi, 1994; Wadsworth, et al., 2008). Bang and Montgomery (2013) employed Q methodology to yield three resultant factors: confident, appreciative, and apprehensive optimists. Sandhu and Asrabadi's (1994) study focused on the principal component analysis to extract six factors: perceived discrimination, homesickness, perceived hate, fear, stress due to culture shock, and guilt. Wadsworth, et al.'s (2008) study used a confirmatory factor analysis to identify five factors: acculturation level, perceived discrimination, personal-enacted identity gap, personal-relational identity gap, and educational satisfaction.

A multiple regression analysis is the last quantitative method in the six reviewed articles (Dao et al., 2007; Jiang et al., 2009; Kashima \& Loh, 2006; Rahman \& Rollock, 2004; Reynolds \& Constantine, 2007; Wang \& Mallinckrodt, 2006). To analyze the hypotheses, Dao et al.'s study (2007) conducted their research via Ordinary Least Squares (OLS) analyses, in which depression was regressed on several independent variables, such as perceived social 
support levels, perceived English fluency, and acculturation levels. Jiang et al.'s (2009) study used multiple regression analyses to see if the dominant society immersion (DSI) scores had an association with oral proficiency scores and pronunciation scores, respectively. Wang and Mallinckrodt's (2006) study employed hierarchical multiple regression analyses (HMR); Kashima \& Loh's (2006) and Rahman \& Rollock's (2004) studies combined multiple regression and factor analyses to measure acculturation indices.

Among the three quantitative methods, multiple regression and factor analyses were employed more than the correlational analysis due to causality and impact. Correlational studies usually lack temporal precedence; thus, they are unable to determine the direction of causality. This sometimes leads to the unconvincing interpretation of data. Similarly, the factor analysis tries to identify relations among variables, but the purpose of the factor analysis is to discover simple patterns in the relationships among the variables, seeking if the observed variables can be explained entirely in terms of a much smaller number of variables called "factors" (Darlington, 2010). Multiple regression is a powerful technique used for predicting unknown values of a variable from the known value of variables. It is evident that quantitative methods (e.g., multiple regression and factor analyses) provide a significant impact on research. However, quantitative studies seem weaker than qualitative ones in terms of SLA in acculturation. This is because a lot of variables in quantitative research do not satisfy the researchers with sufficient accounts of how the international students learn a second language in acculturation.

\subsubsection{Methodologies in Mixed-methods Studies}

Four mixed-methods studies (e.g., Chalupa \& Lair, 2000; Cheng \& Erben, 2012; Kormos et al., 2014; Lee \& Padilla, 2014) are included in this research synthesis. Chalupa and Lair (2000) employed survey questionnaires, which comprised data from a pool of 40 novice and experienced international graduate students, asking any challenges they experienced in the U.S. university regarding the moments of culture shock and any category to which they found most difficult to adjust. Cheng and Erben's (2012) mixed-methods study adopted Horwitz et al.'s (1986) Foreign Language Classroom Anxiety Scale (FLCAS), containing 33 items based on second language learning. Semi-structured interviews were used to 12 students selected from the sample of 156 for the qualitative part of the study. The study investigated students' perceptions of their processes of acculturation and experience of culture shock and whether these factors influenced their English language learning. Kormos et al.'s (2014) study employed survey questionnaires and interviews. The questionnaire aimed to elicit students' views on four aspects of contact experiences: direct spoken and written contact, media contact, and the perceived importance of contact. Interview questions investigated eight main themes: direct spoken and written contact, media contact, perceived importance of contact, instrumental orientation, international orientation, attitudes towards language learning and motivated behaviors. Lee \& Padilla's (2014) study adapted the online questionnaire from Padilla's Societal, Academic, Familial, and Environmental (SAFE) Scale (Mena et al., 1987) and analyzed a total of 22 items following factor analysis. A follow-up interview session was conducted on the open-ended responses in the questionnaire.

In brief, the four mixed-methods studies (i.e., Chalupa \& Lair, 2000; Cheng \& Erben, 2012; Kormos et al., 2014; Lee \& Padilla, 2014) employed survey questionnaires for the quantitative portion and implemented interviews with the surveyed participants for the qualitative portion. Due to the small data, it seems difficult to simplify the trend of mixed-methods research. However, using survey questionnaires wit Likert scales and open-ended items seems prevalent in the studies of SLA in acculturation.

Table 3. Methodology

\begin{tabular}{ll}
\hline Research paradigm & Framework / Methodology \\
\hline Qualitative & Ecological framework (e.g., Poyrazli \& Grahame, 2007); \\
& Naturalistic \& interpretive approach (e.g.,Hebbani \& Hendrix, 2014); \\
& Phenomenological approach (e.g., Lin \& Scherz, 2014; Xue, 2013); \\
& Narrative studies (e.g., Kim, 2012, Liu, 2011) \\
& Correlational method (Lowinger et al., 2014; Noels et al., 1996; Rubenfeld, et al., 2007) \\
Quantitative & Factor analysis (e.g., Bang \& Montgomery, 2013; Sandhu \& Asrabadi, 1994; Wadsworth, et \\
& al., 2008) \\
& Multiple regression analysis (e.g., Dao et al., 2007; Jiang et al., 2009; Kashima \& Loh, 2006; \\
& Rahman \& Rollock, 2004; Reynolds \& Constantine, 2007; Wang \& Mallinckrodt, 2006) \\
& Survey \& interviews (e.g., Chalupa \& Lair, 2000; Cheng \& Erben, 2012; Kormos et al., \\
& 2014; Lee \& Padilla, 2014) \\
\hline
\end{tabular}




\subsection{What Factors Facilitated or Hindered the Participants' Second Language Acquisition and Learning in Their} Acculturation? (Note 4)

\subsubsection{SLA Factors from Qualitative Studies}

The findings from the reviewed qualitative publications show four possible influences of SLA in acculturation: a distance/contact, language deficiency, language power relations, and the participants' academic and linguistic background.

\section{A distance/contact in Acculturation Model}

As Schumann suggested in his acculturation model, the social and psychological distance was an influential factor of the degree of acculturation with regard to SLA. Schumann's acculturation model is when the decreasing social and psychological distance enabled the participants to become more like the target group with an extent of depidginization. Lam's (1994) study agreed with Schumann that learners' acculturation was expedited with the shortening of the social and psychological distance. In addition to Lam's (1994) study, Kormos et al. (2014) and Chalupa \& Lair's (2000) study also supported Schumann's acculturation model. Kormos et al.'s (2014) study indicated that students' infrequent contact with native speakers of English caused a lack of favorable self-efficacy beliefs. The participants acknowledged the significance of experiencing a process of acculturation in order to function as an instructor in the U.S. classroom. However, the participants' acquiring English in acculturation by adopting American mannerisms and culture seemed to be difficult due to their frequent and urgent context of a foreign language classroom. Chalupa and Lair (2000) considered the frequent contact is a critical factor of being acculturated in the target language and culture.

\section{Perceived language deficiency \& inferiority}

Language itself is attributed to SLA in acculturation. Seven studies (i.e., Kim, 2007; Lee, 2009; Liu, 2011; Poyrazli and Grahame, 2007; Xue, 2013; Yan \& Berliner, 2013; Yuan, 2011) among 18 qualitative and mixed-methods publications ascribed perceived language deficiency as a debilitative factor of acculturation. Limited English proficiency was regarded as the most critical factor of the participants' acculturation. The studies revealed that incompetent English language skills hindered active participation and discussions in class. Most of the participants were afraid and challenged to join especially whole class interactions. Poyrazli and Grahame (2007) described students' challenges of discussion-style participations arise from fear of making mistakes and potential ridicules from classmates and professors as well as their perceived inadequacy in English. Yan and Berliner (2013) indicated students' listening problems attributed to a "cultural deficiency" (p. 74), referring to a lack of background knowledge about topics of conversations with their American friends. English language deficiency also leads to passivity in attitude (Kim, 2007; Xue, 2013). In particular, Kim (2007) uncovered that establishing successful advising relationships may be impeded because of Korean students' lack of the target language proficiency and passive attitude towards interacting with their American advisors. Liu's (2011) narrative study also pointed out self-doubt with low self-esteem leads to a struggle to the new language acquisition. For these reasons, perceived language deficiency hinders learners from a success to second language learning in acculturation.

\section{Language power relations}

Language power was mentioned in the four studies (i.e., Kim, 2012; Hsieh, 2007; Yan \& Berliner, 2011; Zhou et al., 2011). Kim (2012) specified that language power relations influence international students' learning a second language in acculturation, and their limited linguistic capital caused a drastic change of their social status and identity. Hsieh's (2007) single case study also implied American classmates' ideology of cultural homogeneity made the participant disempowered and silent in her classes, the participant internalized a deficient self-perception as a useless person in her group discussions. The American ideology of cultural homogeneity results in the failure of the participant's SLA in acculturation. In Yan and Berliner's (2011) study, the overrepresentation of Americans and the English language made some participants tense and psychologically unprepared to be in the environment where English is predominantly governed. Zhou et al.'s (2011) study is also related to language power that the participants invested extra time to adjust to American accents and idioms on U.S. campus.

\section{Academic and linguistic background}

The fourth factor of SLA in the acculturation was international students' background information: academic (Cheng \& Erben, 2012; Hebbani \& Hendrix, 2014) and linguistic background (Lin \& Scherz, 2014; Ren, Bryan, Min, \& Wei, 2007). Cheng and Erben's (2012) study showed that successful language learning in acculturation was closely tied to the students' programs of study. Students who described themselves as being acculturated were able to lower their levels of L2 anxiety. A level of pre-arrival English proficiency was also a factor of L2 learning in acculturation (Ren 
et al., 2007). Additionally, Hebbani and Hendrix's (2014) study revealed that academic levels affected the degree of language learning in acculturation. For example, participating master's students were more afraid of speaking English in public and being cognizant of the cultural distance between their country of origin and the U.S. than PhD students.

\subsubsection{SLA Factors from Quantitative Studies}

The findings from the reviewed quantitative articles also show four possible influences of the participants' L2 acquisition in the acculturation: a distance/contact, language competency, cultural/social aspects, and individual differences.

\section{A distance/contact}

Two studies (Jiang et al., 2009; Noels et al., 1996) attributed a distance/contact to SLA in acculturation. In Jiang et al.'s (2009) study, participants achieved various degrees of SLA in acculturation with a more frequent contact to the dominant society (i.e. the American society). Similarly, Noels et al.'s study (1996) indicated that a greater self-confidence in the second language is related to a frequent contact of the target culture and language. With a frequent contact, using the second language is indicative of better adjustment. Schumann's acculturation model was not employed in the reviewed quantitative studies, which is unexpected, since Schumann's acculturation is closely connected to the cognitive-interactionist views conducted with quantitative research designs. Hence, this would be a good indication that researchers should bear in mind that Schumann's acculturation model may be a better fit to qualitative research related to SLA in acculturation.

\section{Language competency}

Unlike qualitative-based results, quantitative studies provided optimistic views of language competence. Seven quantitative studies (Bang \& Montgomery, 2013; Dao, et al., 2007; Jiang, et al., 2009; Lee \& Padilla, 2014; Noels, et al., 1996; Sandhu \& Asrabadi, 1994; Wang \& Mallinckrodt, 2006) indicated language competency as one of the significantly successful factors of SLA in acculturation. Bang and Montgomery's (2013) Q methodology-based study revealed that international graduate students' communicative competence leads to a greater acculturation with language learning, impacted by their confidence in dealing with cultural and social changes and challenges. In contrast, apprehensive optimistic students seemed to be anxious about their future due to their lack of communicative competence, which contributed to their inability to adapt to life in the US in general and to improve their language learning. Dao et al. (2007) also see perceived English fluency as mediating effects of acculturation level for the international students. Many scholars (Jiang, et al., 2009; Lee \& Padilla, 2014; Noels, et al., 1996; Sandhu \& Asrabadi, 1994) agreed that participants' oral proficiency seemed to influence their SLA in acculturation. Especially, Wang and Mallinckrodt's (2006) findings strongly suggest that English proficiency was significantly negatively associated with international students' acculturation modes, sociocultural adjustment difficulties, and psychological symptoms. So to speak, the international students who have higher self-rated English abilities tend to be more acculturated in the U.S. society and culture with confident communication with the target language group.

Views on cultural/social aspects of English-speaking countries

Quite a lot of publications (i.e., Bang \& Montgomery, 2013; Lee \& Padilla, 2014; Reynolds \& Constantine, 2007; Sandhu \& Asrabadi, 1994; Wadsworth, et al., 2008; Wang \& Mallinckrodt, 2006) provided the evidence of cultural/social aspects as a factor of SLA in acculturation. Bang and Montgomery (2013) stated that resilience, greater acceptance, and openness helped the participants to accomplish their academic goals and to enhance English language proficiency. East Asian apprehensive optimistic students may perceive the cultural gaps as more threatening and therefore struggle to acculturate. Cultural differences in the process of acculturation were found to be an important factor of SLA (Lee \& Padilla, 2014; Reynolds \& Constantine, 2007). Sandhu and Asrabadi (1994) argued that language and cultural differences create further social barriers.

\section{Individual differences}

Similar to qualitative findings, several quantitative studies (i.e., Jiang et al., 2009; Kashima \& Loh, 2006; Lowinger, et al., 2014; Rubenfeld, et al., 2007; Wang \& Mallinckrodt, 2006) paid close attention to individual differences. Quantitative-based researchers regarded individual features as influentially measurable variables. Jiang et al.'s (2009) and Lowinger, et al.'s (2014) studies uncovered that females have been found to hold more positive attitudes towards learning the L2 and treat the L2 as greater value. Gender socialization is an important variable for L2 acquisition. Furthermore, international students' motives and goals best facilitated adaptation to the foreign culture and language in the form of acculturation (Rubenfeld, et al., 2007). The last attribute of SLA was anxiety. Wang and Mallinckrodt's (2006) results suggested that attachment anxiety, one type of affective variables, was negatively associated with 
students' acculturation to U.S. culture and language. The results also indicated that students' acculturation status plays a significant role in sociocultural and psychological adjustment with a critical language factor in the acculturation process.

Table 4. Differences of SLA Factors in the Two Paradigmatic Studies*

\begin{tabular}{lll}
\hline & Qualitative & Quantitative \\
\hline \multirow{3}{*}{ Factors } & A distance/contact in the Acculturation Model & A distance/contact \\
SLA & Perceived language deficiency/inferiority & Language competency \\
& Language power relations & Cultural/social aspects \\
& Academic/linguistic background & Individual differences \\
\hline
\end{tabular}

* The results of SLA factors in the mixed-methods studies are included to each paradigm section, respectively.

\subsection{What Directions Are Recommended for Future Research?}

\subsubsection{Directions in Qualitative Studies}

Among the reviewed qualitative studies, half of them explicitly suggested directions for future research, and the rest proposed pedagogical implications for improving international graduate students' English language learning in their acculturation. Since the previous research was qualitatively conducted, the major recommendations were connected to the size of the population, diverse population, and different scopes in a subject matter (Hebbani \& Hendrix, 2014; Hsieh, 2007; Kim, 2007; Kim, 2012; Lam, 1994; Yuan, 2011).

Lam (1994) and Yuan (2011) recommended studies with larger samples to identify patterns of the population and broader understanding of the acculturation. For instance, Hsieh (2007) stated that to develop a grounded theory, interviewing at least twenty Chinese female international students could enhance the study. For further research on diverse population, Hsieh's (2007) recommendation is to include international students from East Asia. Kim (2007) indicated future studies on advising difficulties in cross-gender relationships. Yuan (2011) suggested a study composed of participants from many different universities would enhance the validity of the research findings on Chinese international students' acculturation. Hebbani and Hendrix (2014) also proposed exploring how skin color impacts on the classroom experience between ITAs and the non-Anglo looking ITA with the Anglo-background. Some implications were related to different scopes in a subject matter (Hsieh, 2007; Kim, 2012; Kim, 2007; Ren et al., 2007; Xue, 2013). Kim (2012) advocated that future studies need to examine how various power relations conjoin in transnational learning and teaching, and how they dynamically generate academic domination beyond the functionalist approach. Kim (2007) considered investigation of other social relations besides academic advising a valuable addition to cross-cultural studies of international students. Xue (2013) specified further study can address the relationships between the time for adjustment to group work and individual variables, such as age, gender, English proficiency, length of stay, educational background, and discipline. Hsieh's (2007) narrative study pointed out that a potential study would be to explore the experience of Chinese international students who keep silent in other higher education, with quantitative measures of their silence.

Besides theoretical and methodological implications, half of the reviewed studies recommended pedagogical implications. These implications comprised two major concerns: institutional and participants-oriented. Most of the studies dealt with an institutional effort for international students' successful acculturation (Chalupa \& Lair, 2000; Cheng \& Erben, 2012; Hsieh, 2007; Lee, 2009; Poyrazli \& Grahame, 2007; Yan \& Berliner, 2011; Yan \& Berliner, 2013; Zhou et al., 2011). Some studies urged that educational institutions should provide training and workshops to enrich international students' acculturation (Chalupa \& Lair, 2000; Cheng \& Erben, 2012). In addition, educators of higher education in English-speaking countries may recognize these students' academic need and then effectively offer supportive campus services (Hsieh, 2007; Lam, 1994; Zhou et al., 2011). Promoting the oral classroom participation of Asian international students was also suggested as a pedagogical implication (Lee, 2009).

Participants-oriented pedagogical concerns were implied in the five studies (Cheng \& Erben, 2012; Kormos et al., 2014; Lam, 1994; Lin \& Scherz, 2014; Liu, 2011). The studies indicated that students should make an effort to adjust themselves to the new academic environment. Developing linguistic abilities, intercultural communication skills and strategies before their arrival in the host country may be necessary (Kormos et al., 2014). A willingness to become autonomous language-learners and develop new learning strategies was also recommended for a success of acculturation (Liu, 2011).

A concluding remark for the future research can be to extend the scope of SLA in acculturation by increasing the 
amount of participants and encompassing diverse contexts to better understand international graduate students' SLA in acculturation. However, it can be said that less scholarship has considered theoretical frameworks of acculturation within social turns in SLA. Therefore, this research synthesis takes into considerations of new directions in acculturation with regard to SLA in the next section.

\subsubsection{Directions in Quantitative Studies}

Most quantitative studies indicated implications theoretically, methodologically, and pedagogically. Four studies (Dao, et al., 2007; Rahman \& Rollock, 2004; Rubenfeld, et al., 2007; Wang \& Mallinckrodt, 2006) delineated variable issues in the implication sections. Dao, et al. (2007) implied the investigation of other variables (e.g., performance expectations, test-taking anxiety, racial discrimination and prejudice) pivotal to international students' adjustment for future research. Likewise, Rahman and Rollock (2004) asserted that incorporating the variables (gender, individual skills, \& educational contexts) into research designs is a crucial step in improving understanding of adaptation. Rubenfeld, et al. (2007) emphasized the relationship between motivational factors and acculturation among different cultures and with larger sample sizes. Wang and Mallinckrodt (2006) stated that further research should investigate the relationship between attachment and acculturation while considering cultural factors is needed. Reynolds and Constantine (2007) paid attention to a sampling from a wider range of institutions throughout all regions of the U. S. necessary to have a complete understanding of the experiences and attitudes of international students. Furthermore, longitudinal research would help to take into account the multidimensional nature of the process (Rahman \& Rollock, 2004; Rubenfeld, et al., 2007). Lee and Padilla (2014) maintained that future studies investigate perceptions of being marginalized on university campuses and influences of their adaptive processes. Kashima and Loh's (2006) study focused on replicating their findings to explore international students' acculturation around the world.

Other four studies (Bang \& Montgomery, 2013; Jiang, et al., 2009; Lowinger, et al., 2014; Wadsworth, et al., 2008) suggested pedagogical implications. Bang and Montgomery (2013) made several suggestions for the development or improvement of programs for international graduate students: enhancing international graduate student programs, improving international student orientation programs, boosting social interactions through graduate student friendship and fellowship programs, and fostering genderspecific group discussions to encourage and help one another. Jiang et al.'s (2009) study signified that immersion activities should be coordinated into formal L2 education programs to facilitate L2 speaking proficiency. Lowinger, et al. (2014) recommended a three-pronged approach that addresses issues of acculturation, academic self-efficacy, and language difficulties in order to help international students' acculturation and adjustment in the U.S. In addition, they proposed that American colleges should organize social events with native students for international students to promote acculturation and improve English language skills.

Wadsworth, et al. (2008) also agreed that colleges and universities in the U.S. should structure classrooms where international students' identities can play an important role and American educational systems in which the challenges that international students may face can be lessened.

\section{Discussion}

\subsection{Comparison of the Research Questions among the Qualitative and Quantitative Research Paradigms}

Regarding construct, contexts, participants, and directions, no significant difference has been found between different paradigmatic studies. Since I targeted international graduate students in English-speaking countries, there is no discrepancy about contexts and participants. Furthermore, all the articles are relevant to acculturation; thus, the authors might as well employ constructs of acculturation, adjustment, and adaptation from related theories, hypotheses, and models. Despite different research paradigms, most articles offered theoretical, methodological, and pedagogical implications in similar patterns.

Different from the research questions above, one research question about factors of SLA provides discrete interpretations among the different research paradigms. First, Schumann's acculturation model does not seem to appear in quantitative studies, which is unexpected since Schumann's acculturation is heavily on the prevalence of cognitive-interactionist views. Hence, this would be a good indication that researchers should bear in mind that Schumann's acculturation model may be a better fit to qualitative research.

Compared to qualitative-based results, quantitative studies provided optimistic views of language competence. In most qualitative studies, a lack of English proficiency was a critical factor of impeding the international students' acculturation and adaptation. This somewhat negative view may be because qualitative researchers are more concerned about the context and environments where students struggle. For example, some studies (e.g., Kim, 2007; 
Poyrazli \& Grahame, 2007; Xue, 2013) pointed out participation and discussions in the classroom setting as the attribute to the hindrance of SLA in acculturation. This perspective is closely related to language power relations, which qualitative researchers emphasized as a main factor of SLA. With an etic viewpoint, environmental factors must be crucial. In this sense, therefore, relations and interactions are the most apparent considerations in qualitative research. With an emic perspective, however, quantitative researchers may not deeply consider circumstantial components significant. They may desire to simplify phenomena with a factor analysis and predict prospective behaviors with regression analyses. The emic or etic aspects of researchers influenced the interpretations of their findings.

Similar to qualitative findings, several quantitative studies (i.e., Jiang et al., 2009; Kashima \& Loh, 2006; Lowinger, et al., 2014; Rubenfeld, et al., 2007; Wang \& Mallinckrodt, 2006) paid close attention to individual differences. In qualitative studies, the researchers focused on individual constructs, such as academic/linguistic backgrounds, as a major contributing factor of acculturation. Quantitative studies regarded individual features-gender, need for cognitive closure, motives, and anxiety — as influentially measurably moderating variables.

\subsection{Prospective Directions of SLA in Acculturation toward Social Turns}

Although Schumann (1990) suggested that the structure and function of the brain might be a good source of ideas about the cognitive architecture and mechanisms involved in SLA in the acculturation process, I would suggest that SLA in acculturation should be discussed in social turns within qualitative research boundaries, based on the findings from the reviewed publications,. Accordingly, this section will deliberate how the factors of the participants' SLA in acculturation - a distance/contact, language competency, language power relations, cultural/social aspects, and individual differences (including the participants' academic and linguistic background) - from both qualitative and quantitative publications. I propose these potential factors of international graduate students' SLA can be possibly shaped and grounded with the frameworks in social turns, such as sociocultural theory (Lantolf, 2011; Vygotsky, 1978), language socialization theory (Duff, 2007; Garrett \& Baquedano-Lopez, 2002), and identity theory (Block, 2007; Norton, 1995, 1997, 2010).

\subsubsection{A distance/contact to Language Socialization Theory}

Several reviewed studies (e.g., Chalupa \& Lair, 2000; Jiang et al., 2009; Kormos et al., 2014; Lam, 1994; Noels et al., 1996) corresponded to Schumann's acculturation model that the social and psychological distance is a crucial actor of the extent of acculturation. This would be matched up with language socialization theory originated in the field of linguistic anthropology (e.g. Ochs \& Schieffelin, 1984). The key tenets of language socialization include social interactions, more proficient members for socializing novices, language to mediate communication and learning, and a lifelong process (Duff, 2007). From the aspect of language socialization, acculturation can be recognized whether students' frequent contact with more proficient speakers of English leads to favorable self-efficacy beliefs and legitimacy of becoming a member in the target society. "Community-of-practice (CoP)" (e.g. Lave \& Wenger, 1991; Wenger, 1998) orientation can be another approach to deal with international students' acculturation. CoP examines the processes that facilitate or obstruct learners' increasing legitimacy and participation within their new learning communities. Therefore, acculturation can be explained by language socialization theory with an ethnographic and longitudinal manner of research.

\subsubsection{Language Competency \& Individual Differences to Sociocultural Theory}

Fourteen studies among 31 publications attributed language competency as a facilitative or debilitative factor of acculturation. In particular, the deficient aspect of acculturation can be intertwined with Vygotskian sociocultural theory of mind (Vygotsky, 1978). Sociocultural theory reconceptualized cognition as social, grounded on social constructivism, which focuses on individual learning in social interactions. Instead of ascribing a lack of language proficiency, the sociocultural theory-based approach may be able to explain the process of language mediation with three kinds of regulation: object, other- and self-regulation (Lantolf \& Thorne, 2007). Object regulation relates objects with the control of the world. Other-regulation refers to the aid of other co-participants. Social speech will occur in the phase of other-regulation. Self-regulation is connected to autonomy in learning. Private speech (an audible speech directed to the self) and inner speech (unobservable to others) may belong to self-regulation (Ortega, 2009). Incompetent English language skills can be explored by the aspect of self-regulation. In Lantolf and Thorne's (2006) study, more proficient learners displayed more traces of self-regulation in their second language choices. In a similar way, researchers can trace less proficient learners who self-doubt with low self-esteem via their inner speech during a self-regulated activity. Kim (2007) and Xue (2013) stated that passivity in attitude resulted from English language deficiency. Passivity may be demonstrated by the participants' inner, private, and social speech in L2 learning. Language deficiency may be the simplest and easiest attribute to explain international graduate students' 
barriers of acculturation (e.g., Lee, 2009; Poyrazli and Grahame, 2007; Xue, 2013; Yan \& Berliner, 2013; Yuan, 2011). Language competency is undoubtedly one of the factors of international students' acculturation. However, researchers need to consider a better way to explore linguistic phenomena within sociocultural theory and other relevant factors of acculturation.

7.2.3 Language Power Relations, Social/cultural Aspects, \& Background Issues to Identity Theory in Poststructuralism

Language power issues (in qualitative research) and social/cultural aspects (in quantitative research) cannot be ignored in SLA, which a particular number of publications dealt with. Notions of investment (Norton Pierce, 1995) and imagined communities (Kanno \& Norton, 2003) will be incorporated into language power relations and learners' background. Identity theory redefines sense of self as socially constructed (Ortega, 2009). Since some of the reviewed studies specified language power relations, identity theory would be considerably commeasurable to discuss them. One significant concept in identity studies is Norton Pierce's (1995) "investment in a learner's own social identity, an identity which is constantly changing across time and space" (p. 17). Learners are recognized to invest in a second language by understanding the acquisition of a broader scope of symbolic and material resources, to increase the value of their "cultural capital" (Bourdieu, 1977, as cited in Norton Pierce, 1995, p. 17). The four reviewed studies related to language power relations have already touched upon identity theory (Kim, 2012; Hsieh, 2007; Yan \& Berliner, 2011; Zhou et al., 2011). Kim (2012) described language power relations prevailed in international students' acculturation and their limited linguistic capital drastically changed their social status and identity. Zhou et al.'s (2011) study also indicated language power as a dominant factor of acculturation that the participants invested extra time to adjust to American accents and idioms on U.S. campus. Several quantitative studies attributed social/cultural aspects of English-speaking countries to SLA in acculturation. As environmental factors, the social/cultural aspects may be connected to power issues and potentially associated with Norton's social identity.

The participants' academic and linguistic background was the fourth factor of acculturation in the reviewed publications. Background issues may be potentially commensurate with "imagined community" (Kanno \& Norton, 2003, p. 241). According to Kanno and Norton (2003), an imagined community refers to "[a group] of people, not immediately tangible and accessible, with whom we connect through the power of the imagination" (p. 241). Some of the background-related issues were uneasiness of dominance of English-speaking people and the English language and unpreparedness of academic acculturation in higher educational settings (Liu, 2011; Yan \& Berliner, 2011). For this reason, pedagogical implications were made to caution that academic institutions have a critical role in implementing the resources needed to help international students have a successful adjustment experience. Creating imagined communities, in particular, may be a possible solution to encounter disengagement of international graduate students.

Table 5. Connections to Social Turns in SLA

\begin{tabular}{|ll|}
\hline A distance/contact & Language socialization (Duff, 2007) \\
Perceived language deficiency & Sociocultural theory \\
Language power relations & (Lantolf, 2011; Vygotsky, 1978) \\
Individual differences & Identity theory (Block, 2007; Norton, 1995, 1997) \\
\hline
\end{tabular}

\section{Conclusion}

This study reviewed 31 studies to investigate how these studies cope with international graduate students' second language acquisition and learning in their acculturation. The research synthesis answered the research questions through conducting the research synthesis. The reviewed articles provided the definition of acculturation, adaptation, and adjustment and delineated contexts of the acculturation, the methodologies and the participants in the studies, factors of acquiring a second language in their acculturation, and recommended directions for future research. Lastly, based on the findings from the reviewed publications, the study discussed how the four influences of the participants' SLA in acculturation (i.e., a distance/contact, language deficiency, language power relations, and the participants' academic and linguistic background) can be possibly shaped and grounded with the frameworks in social turns, such as sociocultural theory (Lantolf, 2011; Vygotsky, 1978), language socialization theory (Duff, 2007; Garrett \& Baquedano-Lopez, 2002), and identity theory (Block, 2007; Norton, 1995, 1997, 2010).

However, much room for further research remains, particularly in examining diverse populations from ESL settings in other East Asian populations. Furthermore, due to the paradigm shift to social turns in SLA, the term, 
"acculturation," seems to become controversial because acculturation implies the full integration of the target culture and language by Schumann's (1986) definition. For this reason, there has been an attempt to use different terms, such as "socialization." In accordance with the unanswered territories, L2 researcher should glean new insights to broaden the field of L2 learning for speculating international graduate students' SLA in acculturation.

\section{References}

References marked with an asterisk indicate studies included in the research synthesis.

Anderson, L. E. (1994). A new look at an old construct: Cross-cultural adaptation. International Journal of Intercultural Relations, 18, 293-328. http://dx.doi.org/10.1016/0147-1767(94)90035-3

Andrade, M. S. (2008). International graduate students: Adjusting to study in the United States, $\ln$ K. A. Tokuno (Ed.), Graduate students in transition: Assisting students through the first year (No. 50, pp.71-90). SC: University of South Carolina.

* Bang, H., \& Montgomery, D. (2013). Understanding international graduate students' acculturation using Q methodology. Journal of College Student Development, 54(4), 343-360. http://dx.doi.org/10.1353/csd.2013.0066

Berry, J. W. (1980). Acculturation as varieties of adaptation. In A. M. Padilla (Ed.), Acculturation: Theory, models and some new findings (pp. 9-25). Boulder, CO: Westview.

Berry, J. W. (1995). Psychology of acculturation. In N. R. Goldberger \& J. B. Veroff (Ed.), The culture and psychology (pp. 457-488). New York: New York University Press.

Berry, J. W. (2005). Acculturation: Living successfully in two cultures. International Journal of Intercultural Relations, 2, 697-712. http://dx.doi.org/10.1016/j.ijintrel.2005.07.013

Berry, J. W. (2006). Acculturative stress. In P. T. P. Wong \& L. C. J. Wong (Eds.), Handbook of multicultural perspectives on stress and coping (pp. 287-298). Dallas, TX: Spring.

Barjesteh, H., Vaseghi, R. (2012). Acculturation Model for L2 acquisition: Review and evaluation. Advances in Asian Social Science (AASS), 2(4), 579-584.

Bialystok, E., \& Ryan, E. B. (1985). A metacognitive framework for the development of first and second language skills. In D. L. Forrest-Pressley, G. E. MacKinnon, \& T. Gary Waller (Eds.), Metacognition, cognition and human performance (pp. 207-249). Orlando, FL: Academic Press.

Block, D. (2003). The social turn in second language acquisition. Washington, DC: Georgetown University Press.

Block, D. (2007). The rise of identity in SLA research, Post Firth and Wagner (1997). Modern Language Journal, 91, 863-876. http://dx.doi.org/10.1111/j.1540-4781.2007.00674.x

Bowers, K. S. (1973). Situationism in psychology: An analysis and a critique. Psychological Review, 80(5), 307-336. http://dx.doi.org/10.1037/h0035592

Casanave, C. P. (2002). Writing games: Multicultural case studies of academic literacy practices in higher education. Mahwah, NJ: Lawrence Erlbaum Associates.

* Chalupa, C., \& Lair, N. (2000). Meeting the needs of international TAs in the foreign language classroom: A model for extended training. Issues in Language Program Direction: A Series in Annual Volumes. Retrieved from ERIC database. (ED481005)

Cheng, L., \& Fox, J. (2008). Towards a Better Understanding of Academic Acculturation: Second Language Students in Canadian Universities. Canadian Modern Language Review, 65(2), 307-333. http://dx.doi.org/10.3138/cmlr.65.2.307

* Cheng, R., \& Erben, A. (2012). Language anxiety: Experiences of Chinese graduate students at U.S. higher institutions. Journal of Studies in International Education, 16(5), 477-497. http://dx.doi.org/10.1177/1028315311421841

* Dao, T. K., Lee, D., \& Chang, H. L. (2007). Acculturation level, perceived English fluency, perceived social support level, and depression among Taiwanese international students. College Student Journal, 41(2), 287-295.

Darlington, R. B. (2010). What factor analysis can and can't do. Factor Analysis. Retrieved from http://www.psych.cornell.edu/darlington/factor.htm

Doughty, C. J., \& Long, M. H. (2003). The handbook of second. language acquisition (Eds.). New York: Blackwell. 
Duff, P. A. (2007). Second language socialization as sociocultural theory: Insights and issues. Language Teaching, 40, 309-319. http://dx.doi.org/10.1017/S0261444807004508

Duff, P. A., \& Talmy, S. (2011). Language socialization approaches to second language acquisition: Social, cultural, and linguistic development in additional languages. In D. Atkinson (Ed.), Alternative approaches to second language acquisition (pp. 95-116). New York: Routledge.

Firth, A., \& J. Wagner. (1997). On discourse, communication and (some) fundamental concepts in SLA research. Modern Language Journal, 81(3), 285-300. http://dx.doi.org/10.1111/j.1540-4781.1997.tb05480.x

Firth, A., \& Wagner, J. (1998). SLA property: No trespassing!. The Modern Language Journal, 82(1), 91-94. http://dx.doi.org/10.1111/j.1540-4781.1998.tb02598.x

García, E. (2001). Understanding and meeting the challenge of student cultural diversity. Boston, MA: Houghton Mifflin.

Garrett, P. B., \& Baquedano-Lopez, P. (2002). Language socialization: Reproduction and continuity, transformation and change. Annual Review of Anthropology, 31, 339-361. http://dx.doi.org/10.1146/annurev.anthro.31.040402.085352

Gass, S. M., \& Selinker, L. (1994). Second language acquisition: An introductory course. Hillsdale, NJ: Lawrence Erlbaum.

Gass, S. M., \& Selinker, L. (2001). Second language acquisition: An introductory course. Mahwah, NJ: Lawrence Erlbaum.

Gasser, M. E. (1988). A connectionist model of sentence generation in a first and second language. (Unpublished doctoral dissertation). University of California, Los Angeles.

Hatch, E., \& Hawkins, B. (1985). Second-language acquisition: An experiential approach. In S. Rosenberg (Ed.), Advances in applied psycholinguistics (pp. 241-283). New York: Cambridge University Press.

* Hebbani, A., \& Hendrix, K. G. (2014). Capturing the experiences of international teaching assistants in the US American classroom. New Directions for Teaching and Learning, 138, 61-72. http://dx.doi.org/10.1002/tl.20097

* Hsieh, M. (2007). Challenges for international students in higher education: One student's narrated story of invisibility and struggle. College Student Journal, 41(2), 379.

Hoekje, B., \& Williams, J. (1992). Communicative competence and the dilemma of international teaching assistant education. TESOL Quarterly, 26(2), 243-269. http://dx.doi.org/10.2307/3587005

Horwitz, E. K., Horwitz, M. B., \& Cope, J. (1986). Foreign language classroom anxiety. Modern Language Journal, 70, 125-132. http://dx.doi.org/10.1111/j.1540-4781.1986.tb05256.x

* Jiang, M., Green, R. J., Henley, T. B., \& Masten, W. G. (2009). Acculturation in relation to the acquisition of a second language. Journal of Multilingual and Multicultural Development, 30(6), 481-492. http://dx.doi.org/10.1080/01434630903147898

Kanno, Y., \& Norton, B. (2003). Imagined communities and educational possibilities: Introduction. Journal of Language, Identity \& Education, 2(4), 241-249. http://dx.doi.org/10.1207/S15327701JLIE0204_1

* Kashima, E. S. \& Loh, E. (2006). International students' acculturation: Effects of international, conational, and local ties and need for closure. International Journal of Intercultural Relations, 30, 471-485. doi:10.1016/j.ijintrel.2005.12.003

* Kim, J. (2012). The birth of academic subalterns: How do foreign students embody the global hegemony of American universities? Journal of Studies in International Education, 16(5), 455-476. $\mathrm{http}: / / \mathrm{dx}$.doi.org/10.1177/1028315311407510

Kim, Y. (2001). Becoming intercultural: An integrative theory of communication and cross-cultural adaptation. Thousand Oaks, CA: Sage.

* Kim, Y. (2007). Difficulties in quality doctoral academic advising: Experiences of Korean students. Journal of Research in International Education, 6(2), 171-193. http://dx.doi.org/10.1177/1475240907078613

Kohls, R. \& Wilson, J. S. (2012). Tutoring adolescents in literacy: A thematic synthesis of published research. In A. Cumming (Eds.), Adolescent literacies in a multicultural context (pp. 23-35). Hoboken, NJ: Taylor \& Francis.

* Kormos, J., Csizer, K., \& Iwaniec, J. (2014). A mixed-method study of language-learning motivation and 
intercultural contact of international students. Journal of Multilingual and Multicultural Development, 35(2), 151-166. doi:10.1080/01434632.2013.847940

Krashen, S. (1985). The input hypothesis. London: Longman.

* Lam, C. (1994). American group discussion patterns as viewed by ESL students: The turn-taking behavior of eight Chinese students studying in America. Retrieved from ERIC database. (ED 379931)

Lantolf, J. P. (2011). The sociocultural approach to second language acquisition: Sociocultural theory, second language acquisition, and artificial L2 development. In D. Atkinson (Ed.), Alternative approaches to second language acquisition (pp. 24-47). New York, NY: Routledge.

Lantolf, J. P., \& Thorne, S. L. (2006). Sociocultural theory and the genesis of second language development. New York: Oxford University Press.

Lantolf, J. P., \& Thorne, S. L. (2007). Sociocultural theory and second language learning. In B. VanPatten \& J. Williams (Eds.), Theories in second language acquisition: An introduction (pp. 197-220). Mahwah, NJ: Lawrence Erlbaum.

Lave, J., \& Wenger, E. (1991). Situated learning: Legitimate peripheral participation. Cambridge: Cambridge University Press.

* Lee, D. S., \& Padilla, A. M. (2014). Acculturative stress and coping: Gender differences among Korean and Korean American University students. Journal of College Student Development, 55(3), 243-262. http://dx.doi.org/10.1353/csd.2014.0025

* Lee, G. (2009). Speaking up: Six Korean students' oral participation in class discussions in US graduate seminars. English for Specific Purposes, 28, 142-156. http://dx.doi.org/10.1016/j.esp.2009.01.007

* Lin, S., \& Scherz, S. D. (2014). Challenges facing Asian international graduate students in the US: Pedagogical considerations in higher education. Journal of International Students, 4(1), 16-33. http://dx.doi.org/10.1.1.686.711

* Liu, L. (2011). An international graduate student's ESL learning experience beyond the classroom. TESL Canada Journal, 29(1), 77-92. http://dx.doi.org/10.18806/tesl.v29i1.1090

Long, M. H. (1996). The role of the linguistic environment in second language acquisition. In W. Ritchie \& T. Bhatia (Eds.), Handbook of second language acquisition (pp. 413-468). New York: Academic Press.

* Lowinger, R. J., He, Z., Lin, M., \& Chang, M. (2014). The impact of academic self-efficacy, acculturation difficulties, and language abilities on procrastination behavior in Chinese international students. College Student Journal, 48(1), 141-152.

McLaughlin, B. (1987). Theories of second-language learning. Baltimore: Edward Arnold.

Mena, F. J., Padilla, A. M., \& Maldonado, M. (1987). Acculturative stress and specific coping strategies among immigrant and later generation college students. Hispanic Journal of Behavioral Sciences, 9, 207-225. http://dx.doi.org/10.1177/07399863870092006

Nizegorodcew, A. (2012). L2 learners' individual differences and the changing SLA perspective. In M. Pawlak (Ed.), New perspectives on individual differences in language learning and teaching, second language learning and teaching (pp. 3-13). Springer-Verlag Berlin Heidelberg.

Norris, J. M. \& Ortega, L. (2007). The future of research synthesis in applied linguistics: Beyond art or science. TESOL Quarterly, 41(4), 805-815. http://dx.doi.org/10.1002/j.1545-7249.2007.tb00105.x

Norton Peirce, B. (1995). Social identity, investment, and language learning. TESOL Quarterly, 29, 9-31. http://dx.doi.org/10.2307/3587803

Norton, B. (1997). Language, identity, and the ownership of English. (Special Issue) TESOL Quarterly, 31(3), 409-429. http://dx.doi.org/10.2307/3587831

Norton, B. (2010), Language and Identity. In N. Homberger \& S. L. McKay (Eds.), Sociolinguistics and Language Education (pp. 349-369). UK: Multilingual Matters.

Ochs, E., \& Schieffelin, B. (1984). Language acquisition and socialization: Three developmental stories and their implications. In R. A. Schweder \& R. Levine (Eds.), Culture theory: Essays on mind, self, and emotion (pp. 276-320). Cambridge: Cambridge University Press. 
Ochs, E., \& Schieffelin, B. (2001). Language acquisition and socialization: Three developmental stories and their implications. In A. Duranti (Ed.) Linguistic anthropology: A reader (pp. 263-301). Oxford, England: Blackwell.

O'Malley, J. M., Chamot, A. U., \& Walker, C. (1987). Some applications of cognitive theory to second language acquisition. Studies in Second Language Acquisition, 9, 287-306. http://dx.doi.org/10.1017/S0272263100006690

Ortega, L. (2009). Understanding second language acquisition. London: Hodder.

* Poyrazli, S., \& Grahame, K. M. (2007). Barriers to adjustment: Needs of international students within a semi-urban campus community. Journal of Instructional Psychology, 34(1), 28-45.

* Rahman, O., Rollock, D. (2004). Acculturation, competence, and mental health among South Asian students in the United States. Journal of Multicultural Counseling and Development, 32, 130-142. http://dx.doi.org/10.1002/j.2161-1912.2004.tb00366.x

Ramsay, S., Barker, M., \& Jones, E. (1999). Academic adjustment and learning processes: A comparison of international and local students in first-year university. Higher Education Research \& Development, 18(1), 129-144. http://dx.doi.org/10.1080/0729436990180110

* Ren, J., Bryan, K., Min, Y., \& Wei, Y. (2007). Language preparation and the first year experience: What administrators and policy makers should know. Florida Journal of Educational Administration \& Policy, 1(1), 11-24.

* Reynolds, A. L., \& Constantine, M. G. (2007). Cultural adjustment difficulties and career development of international college students. Journal of Career Assessment, 15, 338-350. http://dx.doi.org/10.1177/1069072707301218

* Rubenfeld, S., Sinclair, L., Clement, R. (2007). Second language learning and acculturation: The role of motivation and goal content congruence. Canadian Journal of Applied Linguistics, 10(3), 309-323.

* Sandhu, D. S., \& Asrabadi, B. R. (1994). Development of an acculturative stress scale for international students: Preliminary findings. Psychological Reports, 75, 435-448.

Schumann, J. H. (1976). Second language acquisition: The pidginization hypothesis. Language Learning, 26, 391-408. http://dx.doi.org/10.1111/j.1467-1770.1976.tb00283.x

Schumann, J. H. (1986). Research on the acculturation model for second language acquisition. Journal of Multilingual and Multicultural Development, 7(5), 379-392. http://dx.doi.org/10.1080/01434632.1986.9994254

Schumann, J. H. (1990). Extending the scope of the acculturation / pidginization model to include cognition. TESOL Quarterly, 24(4), 667-684. http://dx.doi.org/10.2307/3587114

Swagler, M. A., \& Ellis, M. V. (2003). Crossing the distance: Adjustment of Taiwanese graduate students in the United States. Journal of Counseling Psychology, 50(4), 420-437. http://dx.doi.org/10.1037/0022-0167.50.4.420

Swain, M. (1985). Communicative competence: some roles of comprehensible input and comprehensible output in its development. In S. M. Gass \& C. G. Madden (Eds.), Input in second language acquisition (pp. 235-253). Rowley, MA: Newbury House.

Vygotsky, L. S. (1978). Mind in society: The development of higher psychological processes. MA: Harvard University Press.

* Wadsworth, B. C., Hecht, M. L., \& Jung, E. (2008). The role of identity gaps, discrimination, and acculturation in international students' educational satisfaction in American classrooms. Communication Education, 57(1), 64-87. http://dx.doi.org/10.1080/03634520701668407

* Wang, C., \& Mallinckrodt, B. (2006). Acculturation, attachment, and psychosocial adjustment of Chinese/Taiwanese international students. Journal of Counseling Psychology, 53(4), 422-433. http://dx.doi.org/10.1037/0022-0167.53.4.422

Wenger, E. (1998). Communities of practice: Learning, meaning, and identity. Cambridge: Cambridge University Press.

* Xue, M. (2013). Effects of group work on English communicative competence of Chinese international graduates in United States Institutions of higher education. The Qualitative Report 2013, 18, 1-19. 
* Yan, K., \& Berliner, D. C. (2011). An examination of individual level factors in stress and coping processes: Perspectives of Chinese international students in the United States. Journal of College Student Development, 52(5), 523-542.

* Yan, K., \& Berliner, D. C. (2013). Chinese international students' personal and sociocultural stressors in the United States. Journal of College Student Development, 54(1), 62-84. http://dx.doi.org/10.1353/csd.2013.0010

* Yuan, W. (2011). Academic and cultural experiences of Chinese students at an American university: A qualitative study. Intercultural Communication Studies, 20(1), 141-157.

* Zhou, Y., Frey, C., \& Bang, H. (2011). Understanding of international graduate students' academic adaptation to a U.S. graduate school. International Education, 41(1), 76-94.

\section{Notes}

Note 1. In this paper, second language acquisition and second language learning will be used interchangeably because the process of language acquisition and the process of socialization are interrelated, and the acquisition of adequate uses of language is part of the acquisition of social competence in the involved community (Ochs \& Schieffelin, 2001).Gass \& Selinker (2001) also expressed that "second language acquisition has become inextricably intertwined with language pedagogy" (p. 13).

Note 2. The inclusion criteria consist of several components: the key terms "acculturation" and "second language acquisition and learning" must appear in the article; subjects are Asian graduate students who studied in English-speaking countries; methodology should be specific within three research designs (qualitative, quantitative, or mixed-methods).

Note 3. For the research questions 4 to 6 (methodologies, SLA factors, and directions), I separated qualitative studies from quantitative ones. For the 4 mixed-methods studies, I included them separately in the proper sections.

Note 4. I incorporated the factors of SLA in the mixed-methods studies to each qualitative and quantitative section separately. For example, I included qualitative-based results from Kormos et al.'s (2014) mixed-methods study in the qualitative section, and vice versa. 